\title{
Thai University Students' Use of Yes/No Tokens in Spoken Interaction
}

\author{
Kornsak Tantiwich ${ }^{1} \&$ Kemtong Sinwongsuwat ${ }^{1}$ \\ ${ }^{1}$ Department of Languages and Linguistics, Faculty of Liberal Arts, Prince of Songkla University, Hat Yai \\ Campus, Songkhla, Thailand
}

Correspondence: Kemtong Sinwongsuwat, Department of Languages and Linguistics, Faculty of Liberal Arts, Prince of Songkla University, Hat Yai Campus, Songkhla, Thailand.

\author{
Received: October 13, 2018 Accepted: January 14, 2019 Online Published: January 18, 2019 \\ doi: 10.5539/elt.v12n3p1 URL: https://doi.org/10.5539/elt.v12n3p1
}

\begin{abstract}
Adopting the interactional linguistic framework, the study aimed at exploring the range and frequency of interactional functions of yes/no tokens used by Thai university students of A2 proficiency in their English conversation, and contrasting their use with that of English native speakers (ENSs). The data was derived from 83, two-three party role-play conversations of approximately three-five minutes long obtained from conversation classes that were transcribed and analyzed. The findings revealed the students' use of yes tokens in the following order of functional frequency: acceptance, confirmative response, positive alignment, acknowledgment, topic shift and self-confirmation. By contrast, no tokens were employed most often to disconfirm/disagree, followed by doing disappointment, restatement and negative alignment. Additionally, the students appeared to overuse yes tokens to fulfill certain functions for which ENSs usually deployed other expressions, and had difficulty giving grammatical short answers with the tokens. Furthermore, unlike ENSs, they often used these tokens alone, repeatedly or redundantly with other expressions of the same functions. It was suggested that students be made aware of grammatical expressions that can co-occur with yes/no tokens in giving short answers, and especially of a wider range of expressions commonly used in a specific context and various contexts in which an expression can be appropriately used.
\end{abstract}

Keywords: conversation analysis, conversational language, EFL learners, grammar in talk, language in use, yes/no tokens

\section{Introduction}

The majority of Thai university students have studied English as a foreign language since kindergarten, but their speaking proficiency remains low. There are several reasons for this, one of which appears to be that the main focus of most English courses is on written grammar. The students were mostly taught how to form sentences based on a number of prescribed rules. Often engaged in writing-oriented activities and exercises, the students barely had opportunities to extensively practice speaking English in class. In fact, grammar for talk-in-interaction has hardly ever been focused on in any classes, and neither have students explicitly been made aware of differences between written and spoken language. This might partly contribute to their lack of confidence and spontaneity when they interact with non-Thais in English.

Spoken language contains features that are rather diverse from those of written language features (Biber, Conrad, Leech, \& Finegan, 1999; Sinwongsuwat, 2018). It is full of colloquial and vernacular expressions. Speakers prefer using slang expressions, phrasal verbs and idioms in their talk, and most of the words or sentences in spoken language are often in reduced forms. For example, how is it going? becomes howsitgoin? There are also many eliciting and reactive tokens which reflect the co-constructive nature of talk. Examples of eliciting tokens are you know; you know what I mean; really?; what for?, while reactive tokens include mm, yeah, and ahh, sometimes referred to as back-channeling cues or continuers. Grammatical features found in talk such as modal auxiliaries, adverbials, and many clausal complements allow speakers to express their feelings, attitudes, and assess others, making their personal stances known. Spoken language is also marked by several pauses, fillers (er and $u \mathrm{hm}$ ), and repeats such as yes yes yes; no no no; wait wait wait (Schegloff, 1987; Wong, 2000) because speakers not only have limited time to think about what they want to utter but also are not able to edit their utterances in advance. Finally, language, especially in conversation, contains a large number of shorter phrases, single words and fragments not acceptable in written language. 
Common tokens in talk such as yes/no could pose a serious challenge to students in conversation owing to not only their various functions not found in writing but also their pronunciation which can vary greatly. For instance, such derivatives of the tokens yes and no as yeap and nope occur considerably more frequently than yes and no in spoken interaction (Bartley, 2006; Biber et al., 1999; Eggins \& Slade, 1997). The variety of yes utterances also includes yea, yeah, yep, yay, yup, yeeeeees, yessssss, yiss, y, yaaaaas, and yassssss, referred to as the yes token in this study. On the other hand, the variants of no sounds in causal interactions such as nope, nah, and naw are referred to as the no token.

Based on our observation, Thai university students seemed to utter yes/no tokens often as straightforward responses to closed questions (e.g. Are you hungry? - Yes, I am. or No, I'm not.) or in agreement or disagreement with statements and questions (e.g. A: I think the book is very interesting. - B: yes. It's easy to read, too.). However, in real-time social interaction, yes/no tokens play more multifunctional roles (Eggins \& Slade, 1997; Schegloff, 2001), includeing confirmative responses (Jawhar, 2016); agreement (Drummond \& Hopper, 1993; Jawhar, 2016; Lamertz, 2011); alignment (Lamertz, 2011; Stivers, 2008); acknowledgement (Drummond \& Hopper, 1993; Gardner, 2001; Jawhar, 2016; Jefferson 1984; Jefferson, 1985; McCarthy, 2003); topic shift (Jefferson, 1985; Fuller, 2003); incipient speakership (Gardner, 2007, p. 321; Jefferson, 1983, 1984, 1985, 1993; Drummond \& Hopper 1993) and acceptance (Liddicoat, 2007). On the other hand, the no token also serves a greater number of functions such as a return to a previous topic (Lee-Goldman, 2011); joke-to-serious no token/stance shift (Schegloff, 2001); repair initiation (Schegloff, 1992; Lee-Goldman, 2011); a turn-negotiation token (Lee-Goldman, 2011); command (Lee-Goldman, 2011); rejection to a command (Lee-Goldman, 2011) and despair (Lee-Goldman, 2011).

Because of their wide range of functions and pronunciation, yes/no tokens are ones of the most crucial elements in talks that not only help conversations flow smoothly but also shape speakers' next turn. However, without explicit instruction, students might not be able to fully master their uses. Therefore, the study aimed at exploring the functions of yes/no tokens produced in conversation by Thai university students mostly taught prescriptive grammar. It attempts to identify the most prevalent functions of yes/no tokens and to compare them with those of yes/no tokens used by English native speakers. Therefore, the threefold purposes of the study are (1) to unveil the functions of yes/no tokens Thai university students frequently use in their spoken English interaction; (2) to investigate which functions of yes/no tokens are most prevalent in the Thai students' talks and (3) to determine whether the students' use of the tokens is different from that of English native speakers.

It is hoped that via the interactional linguistic lens, the findings of the study will reveal how the yes/no tokens are used by Thai students differently from those used by English native speakers, raise students and teachers' awareness of different uses of the yes/no tokens in spoken English, and help inform teachers when they design conversation lessons to cover the functions for which the tokens are mostly used by native speakers of English.

\section{Method}

\subsection{Data Collection}

The data examined in this study were video-recorded conversations taken from two corpora. The first corpus was developed as part of a research project investigating the use of Conversation Analysis (CA) to enhance Thai university students' English conversation skills: A study of CA as instructional, exploratory, and diagnostic tools. The data in this corpus was obtained from an elective English conversation course offered at the Faculty of Liberal Arts, Prince of Songkla University, Hat Yai, Thailand. The participants were second- to fourth-year students from different faculties such as Management Sciences, Pharmaceutical Science, and Engineering. They were asked to role-play phone calls according to situations provided such as calling to break off the relationship, deliver good news, make a request, and to order some takeout. Students were given about 10 minutes to prepare for their roleplays. The data examined include 42 telephone conversations, each of which lasts about two or three minutes. There are approximately $30-25$ turns in each conversation. On the other hand, the second corpus was obtained from a fundamental English listening and speaking course taught by one of the researchers, of which the participants were mostly first-year students from the Faculty of Management Sciences. Allowed only 10 minutes to study a situation card, they were assigned to perform unscripted role play in front of the classroom based on a lesson topic given on the card. Their conversations were video-recorded and the data were transcribed, making a corpus of 17 face-to-face conversations, each of which is about three to five minutes long with approximately 40-50 turns.

\subsection{Data Analysis}

This study is contextualized within the interactional linguistic framework. Being one of the descriptive approaches to studying talk-in-interaction, IL is focused on understanding the nature of talks in social interaction 
through their recording and transcription. Interactional linguists believe that the most basic features of natural language are formed and motivated by the home environment in co-present interaction (Schegloff, 1996), and that turns, social actions, and their sequences can only be accomplished and interpreted through the systematic use of linguistic resources (Couper-Kuhlen \& Selting, 2018). Accordingly, IL aims at describing and explaining how linguistic structures shape interaction and vice versa.

In conversation, interactional practices and language have an impact on each other. We use conversation to build social relationships, to negotiate identities, to pass along cultures, and get things done. When we do these, we not only deploy forms of linguistic communication, but also exchange non-verbal language and sometimes silence, and to make sense of these devices, we need to comprehend the context that shapes them, whether linguistic or nonlinguistic and at a macro or micro level (Sinwongsuwat, 2018). To understand the use of yes/no tokens, it is therefore essential to understand the fundamental conversation mechanisms that shape them.

\subsubsection{Turn-Taking}

Turn-taking is one of the most important features that occurs fluidly in conversation. Usually, only one person speaks at a time, and when the current speaker finishes speaking in his or her turn, others can be a next speaker. During transition from a current speaker to another speaker, there might be some gaps and overlaps (Hutchby \& Wooffitt, 1998; Liddicoat, 2007). Without any turns, interaction will not happen (Wong \& Waring, 2010).

Sacks, Schegloff and Jefferson (1974) proposed that the turn-taking system in conversation is both context-free and context-sensitive and is governed by two components: (1) a turn constructional component and (2) a turn allocation component. Turn construction units (TCUs) are made of a variety of grammatical units which can be words, phrases, clauses, and sentences. It is true that people do not only talk in sentences, but also in a wide range of diverse structures. This can be illustrated in the extract below.

(1) [Liddicoat, 2007, p. 55, modified]

1 Joy: hh. so we decided tuh go to that place th's

2 just' opened up.

3 Harry: Where's that

4 Joy: over near dee jays.

5 Harry: oh I haven' seen it.

In excerpt (1), there are four turns, each of which consists of one TCU. All of the TCUs are sentences, except the TCU in line 4, which is a prepositional phrase (PP). The phrasal TCU is treated as a complete, meaningful contribution to the conversation by the talk participants. Namely, once Joy's turn in line 4 is underway, with his interactional competence Harry can project where it will possibly end especially via syntactic and intonational completion cues given; i.e., a PP with a falling intonation at the end of the unit in this case. These cues alongside with actional completion make speaker change possible, rendering a transition relevance places (TRP), where turn transition between speakers can occur. These properties of projectability and transition-relevance place creation are considered essential for the organization of turn-taking (Liddicoat, 2007).

\subsubsection{Sequential Organization}

Talk-in-interaction is usually composed of several turns. Talk participants take turns to keep their conversation going, to coordinate an interactional activity, and to understand each other. Turns in talk are clustered together into sequences. That is, each turn is connected to each other in a systematically organized way, and the relationship between turns is sequentially meaningful (Liddicoat, 2007). The way in which turns are organized in talk is called sequential organization. A question before an answer forms a simple example of a sequence. Other examples include a request followed by the decision made about it, an informative turn and its receipt, and a criticism before the reply to it. All of these different types of sequences are representative of a very firm type of sequence organization, known as the adjacency pair (Mazeland, 2006; Schegloff \& Sacks, 1973; Schegloff, 1968).

Most of the turns at talk come in pairs. An adjacency pair might be a farewell paired with a farewell, a question with an answer, or invitation with acceptance/decline. These kinds of paired utterances are the fundamental units of conversation, and have a normative impact on the organization of conversation because they help set up expectations about how talk will continue.

Adjacency pairs have several main features. They are composed of two turns often formed by different speakers. The two turns are often sequentially delivered. That is, one of them always comes first being a contingency for 
the other one to follow. For instance, a question is uttered before the answer. The first turn is called the first pair part (FPP), whereas the second turn is the second pair part (SPP). The relationship between the two turns is controlled by a FPP. When a FPP occurs at talk, not just any SPP can follow in the next turn, but the SPP that is projected by the FPP. Therefore, a question (FPP) must precede an answer (SPP) not by a greeting or a farewell (Liddicoat, 2007).

\subsubsection{Repair}

Repair is the process through which speakers deal with problems in talk. It is deployed to make sure that an ongoing interaction does not freeze at the moment when a problem occurs (Schegloff, 2007). It not only corrects errors or mistakes in talk (Jefferson, 1987; Schegloff et al., 1977), but also treats unclear pronunciations, malapropisms, use of wrong words, unavailability of proper words in the right contexts, failure to hear or to be heard, problems on the part of the recipient in comprehension (Schegloff, 1987). A repair is of several types, such as (1) self-initiated self-repair, a speaker both identifies a problem and resolves it; (2) self-initiated other-repair, a speaker identifies a problem but a recipient revolves it; (3) other-initiated self-repair, a recipient identifies a problem and a speaker resolves it; and (4) other-initiated other-repair, a recipient both indicates a problem and resolves it.

A repair can also be placed in several positions. First, it can be in the same turn as the problem (same-turn repair). Second, it can be put in the transition space before the turn containing the problem (transition-space repair). Next, it can stay in the turn suddenly following the problem (second-position repair). Also, it can be in a third positioned turn (third-position repair). Finally, it can be placed in a fourth positioned turn (fourth-position repair).

\subsubsection{Transcrition Convention}

The data in this study was analyzed following CA principles based on our understanding of the aforementioned mechanisms. The analysis was aimed at discovering the functions of yes/no tokens used by Thai university students. The most prevalent functions of the tokens uttered were then determined and compared with those reported in the previous literature. The videotaped conversations were transcribed based on the following transcription convention, developed by Gail Jefferson (Hutchby \& Wooffitt, 1998):

(.)

$=$

[ ]

.hh

$\mathrm{Hh}$

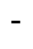

$:$

!

()

(guess)
The number in brackets indicates a time gap in tenths of a second.

A dot enclosed in a bracket indicates a pause in the talk of less than two-tenths of a second.

The 'equals' sign indicates 'latching' between utterances.

Square brackets between adjacent lines of concurrent speech indicate the onset and end of a spate of overlapping talk.

A dot before an ' $h$ ' indicates speaker in breath. The more h's, the longer the in-breath.

An ' $h$ ' indicates an out-breath. The more h's the longer the breath.

A description enclosed in a double bracket indicates a non-verbal activity, or double brackets may enclose the transcriber's comments on contextual or other features.

A dash indicates the sharp cut-off of the prior word or sound.

Colons indicate that the speaker has stretched the preceding sound or letter. The more colons the greater the extent of the stretching.

Exclamation marks are used to indicate an animated or emphatic tone.

Empty parentheses indicate the presence of an unclear fragment on the tape.

The words within a single bracket indicate the transcriber's best guess at an unclear utterance.

A full stop indicates a stopping fall in tone. It does not necessarily indicate the end of a sentence.

A comma indicates a 'continuing' intonation.

A question mark indicates a rising inflection. It does not necessarily indicate a question.

An asterisk indicates a 'croaky' pronunciation of the immediately following section.

Pointed arrows indicate a marked falling or rising intonational shift. They are placed immediately before the onset of the shift. 
a:

$\mathrm{a}:$

Under

CAPITALS

$\circ \circ$

Thaght

$><$

$\rightarrow$

[H:21.3.89:2]

Less marked falls in pitch can be indicated by using underlining immediately preceding a colon.

Less marked rises in pitch can be indicated using a colon which itself is underlined.

Underlined fragments indicate speaker emphasis.

Words in capitals mark a section of speech noticeably louder than that surrounding it.

Degree signs are used to indicate that the talk they encompass is spoken noticeably quieter than the surrounding talk.

A ' $\mathrm{gh}$ ' indicates that the word in which it is placed had a guttural pronunciation.

'More than' and 'less than' signs indicate that the talk they encompass was produced noticeably quicker than the surrounding talk.

Arrows in the left margin point to specific parts of an extract discussed in the text.

Extract headings refer to the transcript library source of the researcher who originally collected the data.

\section{Results}

\subsection{Functions of Yes/No Tokens Used by Thai University Students}

To unveil the sequential functions of yes/no tokens used by Thai university students in their conversation, 59 face-to-face conversations obtained from the two sources previously mentioned were analyzed. The total number of yes and no tokens produced by the students in the entire corpus examined was 132 and 14 times respectively. The percentage of their functional frequency was also determined, and the findings are presented below in Figures 1 and 2 .

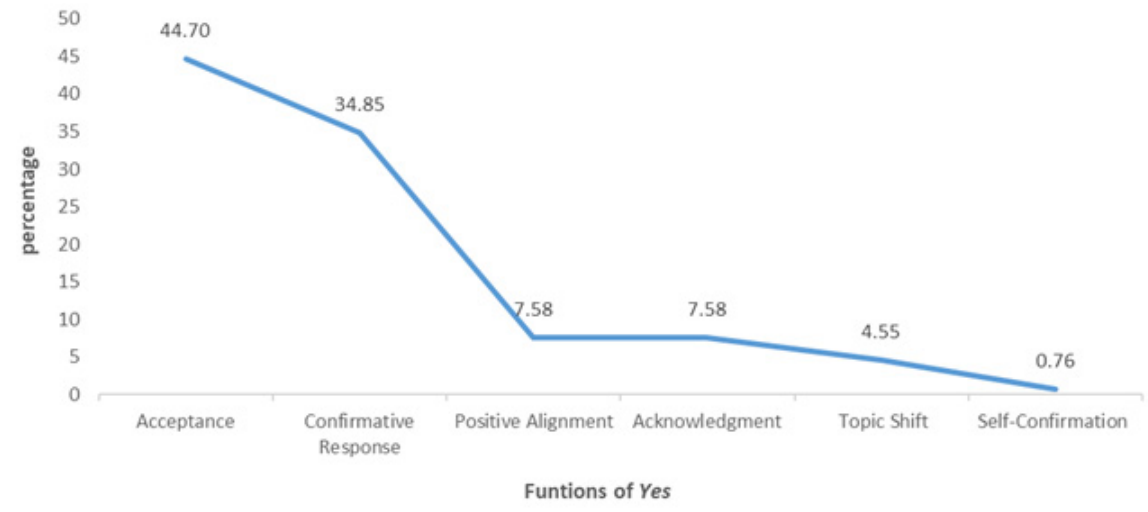

Figure 1. Functions of Yes tokens

As seen in Figure 1, yes tokens were deployed by the students to serve six main functions, the first two of which that were most frequently found were acceptance $(44.70 \%, \mathrm{n}=59)$ and confirmative response $(34.85 \%, \mathrm{n}=46)$ respectively, followed by positive alignment $(7.58 \%, \mathrm{n}=10)$, acknowledgement $(7.58 \%, \mathrm{n}=10)$, topic shift $(4.55 \%$, $\mathrm{n}=6)$ and self-confirmation $(0.76 \%, \mathrm{n}=1)$. The functions that were not found in the corpus examined included the use of yes to show agreement and to signal incipient speakership. This is likely due to the fact that the role-play situation assigned was not conducive to these functions, and that the students were not aware especially of such functions as reserving turn space or showing incipient speakership.

Below are examples of the yes tokens used by the Thai students to serve each of the functions reported. Shown in (2), where both students were asked to role-play a phone call to order a takeout, student A was a server, while student B was a customer. Yes tokens were used three times in lines 3, 4, and 8 for the same function of acceptance. In lines 3 and 8, the tokens were deployed to accept the offer in lines 2 and 7 respectively. Yes in line 4 , on the other hand, can be considered as acceptance of the request in line 3 .

(2) [BT_VDO Phone: 10-06-2559-00020]

1 A: Good morning. You have reached KFC. My name is Wannasa is 


$\begin{array}{llll}\rightarrow & 2 & & \text { receiving your order. How can I help you? } \\ & 3 & \text { B: } & \text { Yes. you can help. I would order double set, please. } \\ & 4 & \text { A: } & \text { Yes, Madam. You order double set. And would you like to add large } \\ & 5 & & \text { size for Pepsi. } \\ 6 & \text { B: } & \text { Uh:::: No. Thank you. } \\ & 7 & \text { A: } & \text { OK. Madam And Would you like to order some breakfast. } \\ & 8 & \text { B: } & \text { Yes, I would. I need two large size for French fries. }\end{array}$

The other most frequently used function was confirmative response. In excerpt (3), student A was acting a role of a waiter in a restaurant, and student B was a customer who asked for a table next to a window. Yes in line 3 was employed as a confirmative response to the yes-no question in line 2 .

(3) [BT_VDO Phone 10-06-2559-00019]

$\begin{array}{llll} & & \text { A: } & \text { Where would you like to sit. } \\ & 2 & \text { B: } & \text { Mmm do you have (0.7) a table (.) by the window. } \\ 3 & \text { A: } & \text { Yes, I do. } \\ 4 & \text { B: } & \text { OK I reserve it. }\end{array}$

The rest of the functions less frequently found include positive alignment (7.52\%), acknowledgement (6.77\%), topic shift (4.51\%), and self-confirmation (0.75\%). Shown in (4), students A, B and C were classmates. Students $\mathrm{A}$ and B were asking student B to go swimming with them on the weekend. Student $\mathrm{C}$ in line 3 was informing student B that they would go swimming in the following weekend. Student A uttered yes in line 4 as positive alignment so as to not only closely align herself with the thought in line 3 but also show that she had the same idea as student $\mathrm{C}$ in line 3 .

(4) [KS_VDO F-F 07-03-2560_03]

$\begin{array}{llll} & 1 & \text { A: } & \text { And do you play sport? } \\ & 2 & \text { B: } & \text { Yes, I do. I play basketball. } \\ & 3 & \text { C: } & \text { We will go swimming on the weekend. } \\ & 4 & \text { A: } & \text { Yes. You can join us. Can you swim? } \\ & 5 & \text { B: } & \text { Absolutely Can I join you the next weekend? }\end{array}$

A typical example of acknowledgement is shown in excerpt (5), a conversation between two friends. In this excerpt, A was telling B about her new job. Before sharing the good news, A gauged if B was ready for the news via the pre-telling turn, Mmm. Jang today I have something to tell you, in line 1. Yes, produced by B in line 2, was thus deployed as acknowledgment or a go-ahead response to the pre-telling. In other words, via B's go-ahead turn, especially the inquiry What about?, A knew that the news was worth telling, thus doing so in lines 3 and 4.

(5) [BT_VDO Phone_10-06-2559-00017]

$\rightarrow \quad \begin{array}{lll}1 & \text { A: } & \text { Mmm. Jang today I have something to tell you. } \\ 2 & \text { B: } & (2.0) \text { yes sure. What about? } \\ 3 & \text { A: } & \text { uhm do you remember (0.7) I already tell you (0.5) that I'm looking for } \\ 4 & & \text { a job and now I got the job already. } \\ 5 & \text { B: } & \text { Wo:w wonderful What is the job? } \\ 6 & \text { A: } & \text { I'm a chef of Thai food }\end{array}$

In excerpt (6), an illustration of the use of the yes token to proffer a topic shift is provided. In this situation, the two speakers, who were friends who had not seen each other for a long while, are making small talk. Student Gap started the conversation with greeting, followed by introducing herself and asking a question to check if the interlocutor could recognize her. Wow! in line 2 shows that meeting Gap was a surprise to Ja. Not expecting to see Gap there, Ja positively confirmed that she could recognize her friend. However, instead of catching up with each other, the students chose to abruptly shift to the formulaic well-being inquiry sequence, lines $3-5$, with Gap's yea::h-prefaced turn in line 3 . The elongation of the word yea: $h$ and the abrupt shift into a new sequence 
apparently make this turn sound inappropriate, not fitting in with the context and diverging from the native speaker's norm, whereby yes is used to offer a shift into a new topic when the interlocutor finds the previous talk uninteresting or inappropriate (Jefferson, 1985; Fuller, 2003).

(6)

$\begin{array}{llll}\rightarrow & 1 & \text { Gap: } & \text { Hello Ja. It's Gap. Do you remember me? } \\ & 2 & \text { Ja: } & \text { Wow! Gap. Yes, I do. } \\ 3 & \text { Gap: } & \text { Yea::h What's up? } \\ 4 & \text { Ja: } & \text { I'm so so. Thank you. And you? } \\ 5 & \text { Gap: } & \text { I'm fi:ne. }\end{array}$

In excerpt (7), the last function of the yes tokens used by the Thai students is self-confirmation. A, a waitress in a pizza restaurant, was taking an order from B.

(7) [BT_VDO Phone_10-06-2559-00033]

1 A: Hello. This is a pizza. How can I help you?

2 B: Yes. I'd like to make an order, please.

3 A: OK. What would you like to order?

4 B: I would like a large Hawaiian pizza with extra cheese, please.

5 A: OK. Hawaiian pizza and extra cheese, please. Would you like anything

$6 \quad$ else?

7 B: Yes. I'd like a glass of Lemonade, please.

8 A: OK. a glass of Lemonade, please.

$9 \quad$ Uh. this is for take out or delivery?

$\rightarrow \quad 10 \quad$ B: $\quad$ Uh:m. take out. (.) yes. please.

11 A: When you take out?

12 B: yes. I'd like to take out.

After having ordered his food and drink, student B was asked in line 9 if he wanted to pick them up by himself or to have the order delivered. B, however, seemed to be undecided. After a moment of thinking, via the use of Uh:m in line 10, he chose to go for a takeout, yet with the following micropause, he was apparently still not sure of his decision, thus using yes to make a final call. Such use of yes is apparently not common among native speakers conversing in a similar context.

To sum up, the yes tokens were evidently used by the Thai students for six main functions including acceptance (44.70\%), confirmative response (34.85\%), positive alignment (7.58\%), acknowledgement (7.58\%), topic shift $(4.55 \%)$, and self-confirmation $(0.76 \%)$. However, the use of yes to show agreement and to signal incipient speakership as reported in previous literature was not found in this study.

While the use of yes tokens was found in six functions, Thai university students used no tokens for three functions, shown in Figure 2. The most frequently found function was disconfirmative response $(78.57 \%, \mathrm{n}=11)$. The frequency of the other functions, including restatement and negative alignment, was equally noted $(7.14 \%$, $\mathrm{n}=1$ each). The functions not found in this study consisted of a return to a previous topic, joke-to-serious no token/stance shift, repair initiation, a turn-negotiation token, command, and rejection to a command. 


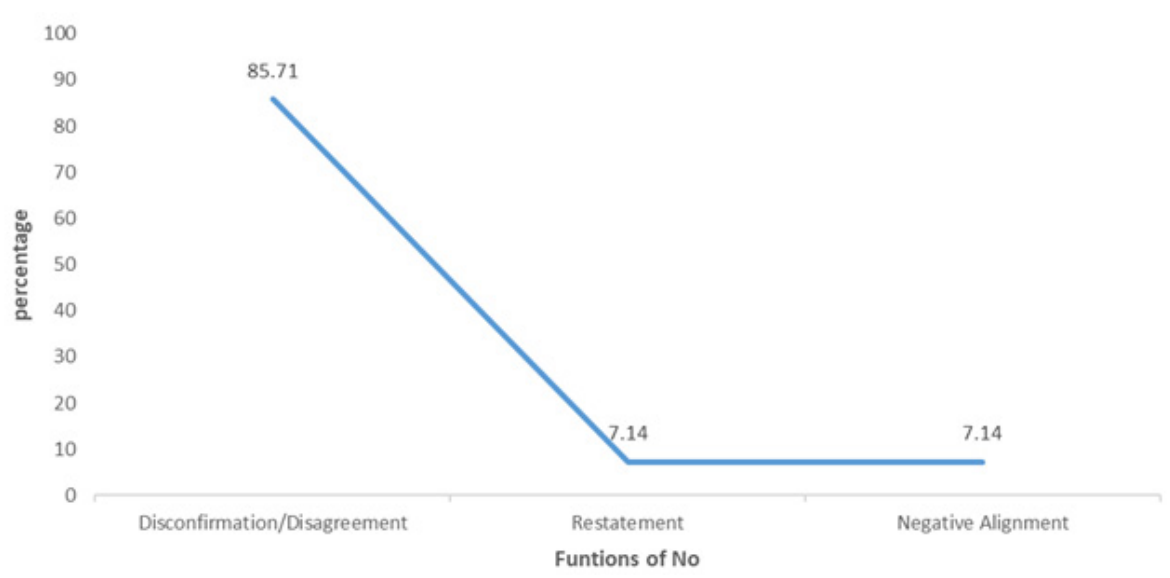

Figure 2. Functions of No tokens

Below are examples of no tokens deployed in conversation by the Thai students examined. Shown in excerpt (8), a no token serves as a disconfirmation in line 6. Student B as a customer was making a dinner reservation at a restaurant where student A was a waitress.

(8) [BT_VDO Phone_10-06-2559-00038]

1 A: OK. Can you come here at 5.45 o'clock to confirm your reservation.

2 B: Yes, I can. I will go there at 5.45.

3 A: OK. We will start to cook your order when you coming confirm it.

4 B: that's so good.

5 A: Do you have anything else?

$\rightarrow \quad 6 \quad$ B: $\quad$ No. I don't think so. Thank you.

In this excerpt, student A asked Do you have anything else? in line 5 to make sure that student B did not want anything else to complete the reservation. In line 6 , student B used a no token to disconfirm the question in the previous turn.

Similarly, in excerpt (9), in which three students were talking about their Saturday's examination, A asked how C had been preparing for the exam, and in line 5, C admitted not having done it with the no token, thus offering a disconfirmative response.

(9) [KS_VDO F-F 06-03-2560_09]

1 A: Ah I know that Uh this Saturday you're going to have an exam.

$2 \quad$ Are you preparing?

3 B: $\quad$ yeah $\uparrow(10.0)$ five subject

4 A: how do you prepare for the exam. (5.0)

$\rightarrow \quad 5 \quad$ C: $\quad$ No

The two other functions of no tokens found in the study were restatement and negative alignment in (10) below. $\mathrm{B}$ and $\mathrm{C}$ were accompanying $\mathrm{A}$ to a swim shop to get a new pair of goggles. Pointing to some imaginary glasses and asking if her friends think they are beautiful, B and C almost simultaneously declined it. B's no in line 2 can be treated as a disconfirmative response with which C's no in line 3 is aligned. A's no in line 4 restates C's uptake, functioning as a confirmative restatement calling the interlocutor's attention to other pairs of glasses.

$$
\begin{array}{llll}
\multicolumn{1}{l}{(10) \text { [KS_VDO F-F }} & \text { 06-03-2560_08] } \\
& 1 & \text { A: } & \text { glasses beautifuls? } \\
\rightarrow & 2 & \text { B: } & \text { no= } \\
\rightarrow & 3 & \text { C: } & \text { no= } \\
\rightarrow & 4 & \text { A: } & \text { no. That blue? } \\
& 5 & \text { C: } & \text { Yes }
\end{array}
$$


6 A: you like (.) you likes pink and blue? or blue?

The functions of no tokens revealed in the study entail disconfirmation, restatement, and negative alignment. Other functions reported in the literature but not found in the students' conversation included a return to a previous topic, joke-to-serious no token/stance shift, repair initiation, a turn-negotiation token, command, and rejection to a command. Besides unconducive situation prompts, the students' elementary English proficiency apparently limited their ability to take longer, multi-unit turns and construct more complicated sequences in which they could switch between various topics, make their opinions known, or negotiate for turn space. The students seemed to also have not yet mastered using no to self-repair, which is a very common means to resolve misunderstanding in natural talk.

\subsection{Differences Between Thai University Students'Use of Yes/No Tokens and English Native Speakers}

Seen in the previous section, Thai students' use of yes/no tokens were fairly limited to a few functions. The yes token in particular was deployed mainly to accept an offer or a request and to confirm facts in the preceding turn, whereas the no token was used primarily for disconfirmation. The students seemed to overuse the tokens while English native speakers (ENSs) may deploy other expressions to fulfill these functions. Apparently, with fairly limited sources in their repertoire, they had to rely particularly on the yes tokens even though ENSs vary their choice of expressions for the same function. Close analysis also revealed differences between their employment of yes/no tokens and that of ENSs in a similar situation. Occurring in single TCUs, the tokens were often used alone, repeatedly, redundantly or ungrammatically as discussed below.

\subsubsection{Stand-Alone Tokens}

Yes/no tokens were employed alone in a single TCU turn by the Thai students, sometimes making it sound abrupt and inappropriate, and this can potentially offend English speakers. As shown in excerpt (11), B offered A to spell the name in line 2 . A accepted the offer by saying yes alone with a flat intonation in line 3 .

(11) [BT_VDO Phone_10-06-2559-00035]

1 A: May I have you name, please

2 B: Yes My name is Jane. Can I spell that?

$\rightarrow \quad 3$ A: Yes.

4 B: J-A-N-E

To make the turn sound more polite to the interlocutor, the yes token could actually be used with other expressions to accept an invitation or an offer such as yes please and yes thank you as shown in excerpts (12) and (13).

(12) [Living English, Ep.2, Australian Plus, 2016]

1 Clern: Good morning. Would you like to check in?

$\rightarrow \quad 2$ Anne: $\quad$ Yes please.

3 Clerk: And your name?

4 Anne: Anne Lee.

In (12), Anne was checking into a hotel. In line 1, after a greeting, the clerk invited her to check in, to which Anne responded not only with the token yes but the politeness expression please. Additionally, to accept an offer, NSs also often use politeness expressions without the token yes.

(13) [extr@ English 01 - Hector's Arrival, P9, (Extr@English, 2013a, April 24)]

1 Nico: What should I do?

2 Elke: Apply. The Job is ideal for you. You don't want to be a trainee

$3 \quad$ forever, do you?

4 Nico: Definitely not!

5 Elke: The application form - like this - you can get one from the

6 Personnel Department on the second floor. I'll help you with it.

$\rightarrow \quad 7$ Nico: $\quad$ Many thanks.

As shown in excerpt (13), Elke not only suggests that Nico apply for the job but also offers to help her with it, 
and Nico accepts Elke's offer by expressing gratitude, Many thanks, in line 7 without even using the yes token.

Not only can stand-alone yes tokens make them sound unnatural or impolite to English speakers, but their no tokens can also sound rude as in excerpt (14) below.

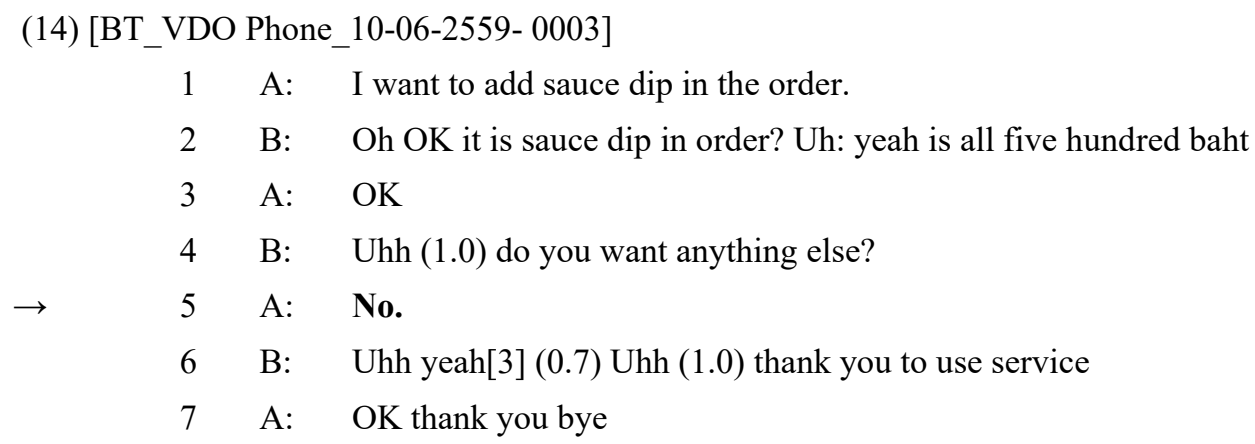

In this excerpt, $\mathrm{A}$ asked $\mathrm{B}$ to add a dipping sauce to the order and after being told the cost and asked if anything else was to be included in the order, A delivered no quite bluntly with a falling intonation in line 5 , which could sound rude to English speakers. The latter likely uses the no token more often with other expressions such as No thanks/thank you, and Nope, that's it. One of the examples is illustrated in excerpt (15) below.

(15)

$\begin{array}{llll} & 1 & \text { Water: } & \text { Would you like some more coffee? } \\ & 2 & \text { Customer: } & \text { No, thank you, I'm fine. }\end{array}$

Thai students, therefore, need to be made aware of polite expressions and various other expressions they can use to appropriately accept an offer in English.

\subsubsection{Repetitive/Redundant Tokens}

Occasionally, the tokens were also unnecessarily repeated twice or more. In excerpt (39), B apparently used yes to strengthen their confirmative preface yeh and repeated part of their interlocutor's preceding turn.

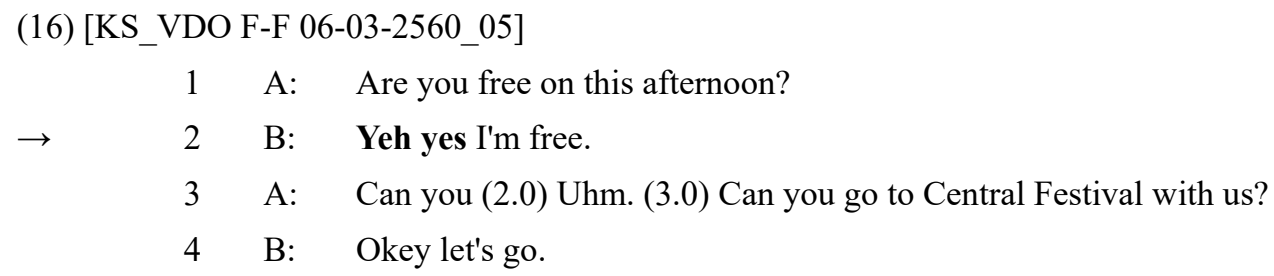

Such repetition of given information in the previous turn is apparently not very common among ENSs as we often find the token used with a short answer or other expressions, e.g., Yes, why/what's up?, What's up?. One of the examples is shown in excerpt (17) below.

(17) [extr@ English 30 - Love Hurts-2, P182 (Extr@English, 2013b, April 24)]

$\begin{array}{llll}1 & \text { Bridget: } & \text { What are you wearing? } \\ 2 & \text { Nick: } & \text { I am a toreador! } \\ 3 & \text { Hector: } & \text { Oh! Oh! Olé!! } \\ 4 & \text { Nick: } & \text { Whose is this?! } \\ 5 & \text { Annie: } & \text { Bridget's. } \\ 6 & \text { Nick: } & \text { You are taking all that?! } \\ 7 & \text { Bridget: } & \text { Yeah, why? } \\ 8 & \text { Nick: } & \text { Oh Bridget, Bridget, Bridget - all you need to travel is your } \\ 9 & & \text { passport, your tickets and your money, ha-ha! }\end{array}$

Additionally, the no token was similarly repeated without any accentuation or strong disagreement involved, different from those used by ENSs as in excerpt (18).

(18) [KS_VDO F-F 07-03-2560_08] 


\section{A: Have you ever been to Thailand? \\ $\rightarrow \quad 2 \quad$ B: no no no Ah! one time one time}

In this excerpt, A asked B about B's travel experience. In line 2, the no token was repeated three times prior to self-repair. This is quite different from ENSs' use of the token, whereby the token is usually produced only once with accompanying expressions such as no never been there, or no, I have not been there. One of the examples is demonstrated in excerpt (19) below.

(19) [extr@ English 30 - Love Hurts-2, P36 (Extr@English, 2013b, April 24)]

$\begin{array}{llll} & 1 & \text { Nick: } & \text { Ha-ha! You ordered melons instead of lemons and too many } \\ & 2 & & \text { eggs. Have you ever been to a supermarket? } \\ 3 & \text { Hector: } & \text { No. My ... } \\ 4 & \text { Nick: } & \text { Who are these? } \\ 5 & \text { Hector: } & \text { My ... } \\ 6 & \text { Nick: } & \text {.. Servants. } \\ 7 & \text { Hector: } & \text { Yeah, my servants.. }\end{array}$

Furthermore, it was found that yes/no tokens were redundantly used by the students with other expressions serving the same function. For instance, yes co-occurs with OK as in excerpt (20).

$$
\begin{array}{llll} 
& 1 & \text { A: } & \text { Have you got time for a coffee? } \\
& 2 & \text { B: } & \text { Yes, } \text { OK. Where do you want to go? }
\end{array}
$$

As seen in (20), A invited B to have some coffee together. B accepted the invitation in line 1 with both Yes and $O K$, which do the same action, acceptance of invitation. The latter does not add any force to the preceding yes, making it different from the use by most ENSs who usually strengthen the force of the confirmative token with another accentuating element as in yes of course, definitely yes. and absolutely yes as shown in excerpt (21).

(21)

$\begin{array}{llll}1 & \text { Hector: } & \text { Good evening and a very warm well...come to Channel Nine's } \\ 2 & & \text { Eurobabe Contest live! } \\ 3 & \text { Bridget: } & \text { Yes, OK, get on with it! } \\ 4 & \text { Hector: } & \text { Have we got some lovely ladies for you tonight. Have we? } \\ 5 & \text { Bridget: } & \text { Yes, of course we have. } \\ 6 & \text { Hector: } & \text { Oh, oh, yes, yes, we have. Of course we have. } \\ 7 & & \text { So let's meet our lovely contestants eager to wear the Channel } \\ 8 & & \text { Nine Eurobabe Crown! }\end{array}$

In (21), the token yes is evidently used by NSs with other tokens strengthening the force of the confirmative token. In line 5, Bridget not only deployed yes to confirm Hector's question in line 4 but also said of course to emphasize the confirmation.

\subsubsection{Ungrammatical Use With Other Expressions}

The Thai students apparently had problems with delivering appropriate short answers in response to confirmative questions with the yes/no tokens. In fact, it was found that the tokens were often used along with the subject of the question and an ungrammatical verb. They especially tended to misuse the auxiliary verb when making a short answer to dis/confirm the previous turn as shown in excerpt (45) below.

(22) [BT_VDO Phone_10-06-2559-00031]

$$
\begin{array}{llll} 
& 1 & \text { A: } & \text { Do you want anything esle? } \\
& 2 & \text { B: } & \text { Do you have Coca-Cola. } \\
\rightarrow \quad & 3 & \text { A: } & \text { Yes, I have. }
\end{array}
$$


In (22) line 3, instead of saying yes, we/I do, A used the main verb instead, apparently appealing to their mother tongue which is an isolating language with no auxiliary use.

Based on these differences, it can be argued that although the Thai students' use of the yes/no tokens may be greatly influenced by the nature of their real-time moment-by-moment interaction, their limited interactional competence resulting from past learning experience and the mother-tongue influence cannot be understated either. The students should be taught how to construct appropriate, multi-unit turns not to sound rude to their interlocutors and how to efficiently maintain conversation such that their goals can easily be achieved. Additionally, they should be made more aware of the fact that repetition and redundancy in language use may be more tolerable among speakers of high-context cultures such as Thais but they are apparently less preferable among those preferring more direct and explicit communication of ideas such as English (Nishimura, Nevgi, \& Tella, 2008).

\section{Conclusion}

This study examined the functions of yes/no tokens used in Thai students' English conversation and contrasted them with those often found in the discourse of English native speakers. The analysis results revealed six main functions of yes tokens deployed by the Thai students in the order of frequency, including acceptance, confirmative response, positive alignment, acknowledgement, topic shift, and self-confirmation. Notably, however, there were only two functions for which the yes tokens were most often used, acceptance and confirmative responses. On the other hand, there were only three functions of no tokens found in this study, namely disconfirmation, restatement, and negative alignment. No tokens as disconfirmation were the most frequently found among the three. Overall, there remained several other functions of the tokens found in ENSs' use such as the use of yes to show agreement and to signal incipient speakership, as well as other functions of no never unused such as nos as a return to a previous topic, a stance shift from joke-to-serious, repair initiation, a turn-negotiation token, a command, and rejection to a command. It was very likely that besides the unconducive nature of the role-play situation prompts, the students were not really aware of these functions and never taught how to use the tokens to fulfill those functions. Additionally, among the functions of the tokens found, problems occurred regarding the appropriateness of use as the yes/no tokens were often deployed alone with inappropriate intonation, unnecessarily repeated, and redundantly or ungrammatically used with other expressions, which may cause misunderstanding and make them appear rude to other English speakers.

Therefore, it was recommended that to enhance L2 interactional efficiency, students need to be taught any L2 expressions with reference to not only their actual context of use but their various possible functions and cultural implications. Particularly, via authentic examples of language in naturally-occurring conversation, the students should be made cognizant of intonation features of speech as well as other expressions that can possibly be used with the target expressions to construct turns to accomplish their interactional goals and especially of various sequential interactional contexts of talk in which these expressions can possibly be used. Further research may explore other problems in language use of these learners and examine their talk in various other interactional settings.

\section{Acknowledegments}

The authors would like to acknowledge Prince of Songkla University, Hat Yai, Thailand for the research grant \#LIA 590389S, without which this research undertaking would not have been possible. Contributions from all the parties involved in the research were also greatly appreciated.

\section{References}

Australia Plus. (2016, April 5). Living English Ep 2. Learn English: Living English Series. Retrieved from http://www.australiaplus.com/international/learn-english/living-english-index-page/7941298

Bartley, A. (2006). 2 ways to talk (casual and formal)... in the English language. Retrieved from https://www.talktocanada.com/blog/2-ways-to-talk-casual-and-formal-in-the-english-language/

Biber, D., Conrad, S., Leech, G. N., \& Finegan, E. (1999). Longman Grammar of Spoken and Written English. Harlow, Essex: Perason Education Limited.

Couper-Kuhlen, E., \& Selting M. (2018). Interactional linguistics: Studying language in social interaction. Cambridge CB2 8BS, UK: Cambridge University Press.

Drummond, K., \& Hopper, R. (1993). Some uses of yeah. Research on Language and Social Interaction, 26(2), 203-212. https://doi.org/10.1207/s15327973rlsi2602_6

Eggins, S., \& Slade, D. (1997). Analyzing casual conversation. London, UK: Equinox Publishing Ltd. 
Extr@English. (2013a, April 24). Hector’s arrival.

Extr@English. (2013b, April 24). Love hurts.

Ford, C. E., Fox, B. A., \& Hellerman, J. K., (2004). "Getting past no": Sequence, action, and sound production in the production of no-initiated turns. In E. Couper-Kuhlen, \& C. Ford (Eds.), Sound patterns in interaction: Cross-linguistic studies from conversation (pp. 233-272). Amsterdam, Netherlands/Philadelphia, US: John Benjamins Publishing Company. https://doi.org/10.1075/tsl.62.13for

Fuller, J. M. (2003). The influence of speaker roles on discourse marker use. Journal of Pragmatics, 35, 23-45. https://doi.org/10.1016/S0378-2166(02)00065-6

Garber, M. (2015). How to say 'yes' (by not saying 'yes'). Retrieved from https://www.theatlantic.com/ technology/archive/2015/04/how-to-say-yes-by-not-saying-yes/390129/

Garder, R. (2001). When listeners talk: Response tokens and listerner stance. Amsterdam, The Netherlands: John Benjamins Publishing Company. https://doi.org/10.1075/pbns.92

Hutchby, I., \& Wooffitt, R. (1998). Conversation analysis. Cambridge, UK: Polity Press.

Jawhar, S. S., (2016). Small but multi-functional: Response tokens in content language integrated learning interaction. Arab World English Journal (AWEJ), 7(4), 258-276. https://doi.org/10.24093/awej/vol7no4.17

Jefferson, G. (1983). Issues in the transcription of naturally-occurring talk: Caricature versus capturing pronunciational particulars. Tilburg Papers in Languge and Literature, 34, 1-12. Tilburg: Tilburg University.

Jefferson, G. (1984). On stepwise transition from talk about a trouble to inappropriately next-positioned matters. In J. M. Atkinson, \& J. C. Heritage (Eds.), Structures of social action: Studies of conversation analysis (pp. 191-222). Cambridge, UK: Cambridge University Press.

Jefferson, G. (1985). Notes on a systematic deployment of the acknowledgement tokens "yeah" and "mm hm." Papers in Linguistics, 17, 197-216. https://doi.org/10.1080/08351818409389201

Jefferson, G. (1987). 'On exposed and embedded correction in conversation.' In G. Button, \& J. R. E. Lee (Eds), Talk and social organization. (pp. 86-100). Clevedon, Avon: Multilingual Matters.

Jefferson, G. (1993) Caveat speaker: Preliminary notes on recipient topic-shift implicature. Research on Language and Social Interaction, 26(1), 1-30. https://doi.org/10.1207/s15327973rlsi2601_1

Jefferson, G. (2002). Is "no" an acknowledgement token? Comparing American and British uses of (+)/(-) tokens. Journal of Pragmatics, 34, 1345-1383. https://doi.org/10.1016/S0378-2166(02)00067-X

Lamertz, K. (2011). Back-channelling: The use of yeah and $\mathrm{mm}$ to portray engaged listenership. Griffith Working Papers in Pragmatics and Intercultural Communication, 4(1/2), 11-18.

Lee-Goldman, R. (2010). No as a discourse marker. Journal of Pragmatics, 43, 2627-2649. https://doi.org/10. 1016/j.pragma.2011.03.011

Liddicoat, A. J. (2007). An introduction to conversation analysis. London: Continuum.

Mazeland, H. (2006). Conversation Analysis. University of Groningen, Groningen, The Netherlands: Elsevier Ltd.

McCarthy, M. (2003). Talking back: "Small" interactional response tokens in everyday conversation. Research on Language \& Social Interaction, 36(1), 33-63. https://doi.org/10.1207/S15327973RLSI3601_3

Nishimura, S., Nevgi, A., \& Tella, S., (2008) Communication Style and Cultural Features in High/Low Context Communication Cultures: A Case Study of Finland, Japan and India. Retrieved from http://www.helsinki.fi/ tella/nishimuranevgitella299.pdf

Oliver, D. (2007). Conversational language (\#7): Informal variations on "yes." Retrieved from http://www.eslcafe.com/grammar/conversational_language 07.html

Sacks, H., \& Schegloff, E. A. (1979). Two preferences in the organization of reference to persons in conversation and their interaction. In G. Psathas (Ed.), Everyday language: Studies in Ethnomethodology (pp. 15-21). Hillsdale, NJ: Lawrence Erlbaum.

Sacks, H., Schegloff, E. A., \& Jefferson, G. (1974). A simplest systematics for the organization of turn-taking for conversation. Language, 50, 696-735. https://doi.org/10.2307/412243

Schegloff, E. (1968). Sequencing in conversational openings. American Anthropologist, 70, 1075-1095. 
https://doi.org/10.1525/aa.1968.70.6.02a00030

Schegloff, E. A. (1972). Notes on conversational practice: Formulating place. In D. Sudnow (Ed.), Studies in social interaction (pp. 75-119). New York: Free Press.

Schegloff, E. A. (1982). Discourse as an interactional achievement: Some uses of 'uh huh' and other things that come between sentences. In D. Tannen (Ed.), Analyzing discourse: Text and talk (pp. 71-93). Washington, DC: Georgetown University Press.

Schegloff, E. A. (1987). Recycled turn beginnings: A precise repaire mechanism in conversation's turn-taking organization. In G. Button, \& J. R. E. Lee (Eds.), Talk and social organization (pp. 70-85). Clevedon, UK: Multilingual Matters.

Schegloff, E. A. (1992). Repair after next turn: The last structurally provided defense of intersubjectivity in conversation. American Journal of Sociology, 97(5), 1295-1345. https://doi.org/10.1086/229903

Schegloff, E. A. (1995). Discourse and an interaction achievement III: The omnirelevance of action. Research on Language and Social Interaction, 28(3), 185-211. https://doi.org/10.1207/s15327973rlsi2803_2

Schegloff, E. A. (2001). Getting serious: Joke $\rightarrow$ serious 'no'. Journal of Pragmatics, 33, 1945-1955. https://doi.org/10.1016/S0378-2166(00)00073-4

Schegloff, E. A. (2007). Sequence organization in interaction: A primer in conversation analysis. Cambridge, UK: Cambridge University Press. https://doi.org/10.1017/CBO9780511791208

Schegloff, E. A., \& Sacks, H. (1973). Opening up closings. Semiotica, 7, 289-327. https://doi.org/10.1515/ semi.1973.8.4.289

Schegloff, E. A., (1996). Turn organization: One intersection of grammar and interaction. In E. Ochs, E. A. Schegloff, \& S. A. Thompson (Eds.), Interaction and grammar (pp. 52-133). Cambridge: Cambridge University Press. https://doi.org/10.1017/CBO9780511620874.002

Schegloff, E. A., Jefferson, G., \& Sacks, H. (1977). The preference for self-correction in the organization of repair in conversation. Lanuage, 53, 361-82. https://doi.org/10.2307/413107

Schourup, L., (1999). Discourse markers. Lingua, 107, 227-265. https://doi.org/10.1016/S0024-3841(96)90026-1

Seedhouse, P. (2004). The interactional architecture of the language classroom: A conversation analysis perspective. Malden, US: Blackwell. Social Interaction, 33(4), 407-424.

Stivers, T., (2008). Stance, alignment, and affiliation during storytelling: When nodding is a token of affiliation. Research on Language and Social Interaction, 41(1), 31-57. https://doi.org/10.1080/08351810701691123

Viney, B. (2003). The history of the English Language. Oxford: Oxford University Press.

Wong, J., \& Waring, H. Z., (2010). Conversation analysis and second language pedagogy. London, UK: Taylor \& Francis. https://doi.org/10.4324/9780203852347

Wong, J. (2000). Repetition in conversation: A look at "First and second sayings." Research on Language and Social Interaction, 33(4), 407-424. https://doi.org/10.1207/S15327973RLSI3304_03

\section{Copyrights}

Copyright for this article is retained by the author(s), with first publication rights granted to the journal.

This is an open-access article distributed under the terms and conditions of the Creative Commons Attribution license (http://creativecommons.org/licenses/by/4.0/). 